\title{
Melatonin as a chronobiotic/cytoprotector: its role in healthy aging
}

\author{
Daniel P. Cardinali \\ Departmento de Docencia e Investigación, Facultad de Ciencias Médicas, Pontificia \\ Universidad Católica Argentina, 1107 Buenos Aires, Argentina.
}

Contact: danielcardinali@fibertel.com.ar. Web site: $\underline{\text { www.daniel- }}$ cardinali.blogspot.com

Word count: 9207 words

\begin{abstract}
Preservation of sleep, a proper nutrition and adequate physical exercise are key elements for healthy aging. Aging causes sleep alterations, and in turn, sleep disturbances lead to numerous pathophysiological changes that accelerates the aging process. In the central nervous system, sleep loss impairs the clearance of waste molecules like amyloid- $\beta$ or tau peptides. Melatonin, a molecule of unusual phylogenetic conservation present in all known aerobic organisms, is effective both as a chronobiotic and a cytoprotective agent to maintain a healthy aging. The late afternoon increase of melatonin "opens the sleep doors" every night and its therapeutic use to preserve slow wave sleep has been demonstrated. Melatonin reverses inflammaging via prevention of insulin resistance, suppression of inflammation and down regulation of proinflammatory cytokines. Melatonin increases the expression of $\alpha$ - and $\gamma$-secretase and decreases $\beta$-secretase expression. It also inhibits tau phosphorylation. Clinical data support the efficacy of melatonin to treat Alzheimer's disease, particularly at the early stages of disease. From animal studies the cytoprotective effects of melatonin need high doses to become apparent (i.e. in the $40-100 \mathrm{mg} /$ day range). The potentiality of melatonin as a nutraceutical is discussed.
\end{abstract}

Keywords: aging; neuroprotection; sleep physiology; Alzheimer's disease; inflammaging

Funding details: Studies in author' laboratory were supported by grants PICT 2007 01045 and 20120984 from the Agencia Nacional de Promoción Científica y Tecnológica, Argentina.

Disclosure: No potential conflict of interest is reported by the author. 


\section{Introduction}

There is no universally accepted medical definition of aging. It has been defined as the progressive accumulation of changes that occur over time and cause increased likelihood of disease and death of the individual (Harman, 1981). Aging can be defined through four postulates: 1 . Aging is universal, i.e., phenomena associated with the aging should be given at a greater or lesser extent in all individuals. 2. Aging is intrinsic, i.e., its cause should be of endogenous origin, and not depending on external factors or environmental origin. 3. Aging is progressive: changes that lead to aging occur gradually throughout life. 4 . Aging is deleterious, i.e. a phenomenon is only considered part of the aging process if harmful (Burkle, 2002).

Virtually all physiological functions become less efficient with age. For example, slow wave sleep decreases exponentially with aging and often disappears after 55-60 years of age (Branger et al., 2016). Many elderlies complain of an interrupted sleep and of daytime sleepiness. Other common complaints are the early awakenings and a poor capacity to maintain alertness at the evenings. Both are indexes of the aging of the circadian apparatus: a decrease in amplitude and phase-advance of circadian rhythms. Because of the reduction in neuron number in the central circadian pacemaker, the hypothalamic suprachiasmatic nuclei (SCN), the sequence and spacing of the maximum values of daily rhythms are progressively lost (Duffy et al., 2015, Gubin et al., 2016).

In aging there is a homeostatic reduction of the capacity to maintain stable the internal environment of the individual against environmental disturbances (Cardinali, 2017). An example of this is the reduced ability of the elderly to withstand extreme temperatures, trauma, infections, and stress in general. With aging most vital organs suffer atrophy or degeneration phenomena. This is most noticeable in differentiated cells such as neurons, myocardial cells, muscle cells or the renal parenchyma.

The average longevity of the human species has increased considerably throughout history due to the decline in infant mortality, the discovery of antibiotics, vaccines and, more generally, to the improvement of the control of infectious diseases, as well as a more balanced nutrition, better sanitary conditions, and advances in the treatment of diseases such as cancer or diabetes. In contrast maximal longevity has remained unmodified. The increase in average longevity is seen in the growing segment of the population between 60 and 100 years. Those over 80 are now $1.6 \%$ of the world population and by 2050 they will reach $4.3 \%$ (about 400 million people). Considering that the estimation for number of Alzheimer's disease (AD) patients for 2050 is 150 million people it has become very important the goal of "successful aging" to avoid the consequences of neurodegenerative diseases, cancer or arteriosclerosis, i.e., those affecting most likely this elderly group (Zdanys and Steffens, 2015).

It is generally accepted that cell disruption due to oxidative stress caused by free radicals is a major physiopathologic event in aging (Bhatti et al., 2017). In addition, other current hypotheses suggest a direct relationship between aging, genetic programs and telomere loss that occurs in each cell division leading to apoptotic cell death. Although all these processes and mechanisms are probably involved in diseases associated with aging, their role in normal aging of organisms has not yet been clarified. 


\section{Aging of Sleep}

Sleep can be defined as a reversible behavioural state of perceptual disengagement from and unresponsiveness to the environment (Cirelli and Tononi, 2008). An adequate amount and quality of daily sleep are among the keys for healthy aging. The exact amount of sleep needed for optimal human health, however, shows significant inter- and intra-individual variation.

The relationship between sleep and aging is bidirectional (Mazzotti et al., 2014). Inadequate sleep, both in terms of its duration and quality, can affect health and thus adversely contribute to the aging process. On the other hand, sleep difficulties typically increase with age as a result of flattening and misalignment of circadian rhythms like that of melatonin secretion, as well as of the sleep-disturbing influences of agingrelated disorders and diseases (Hardeland, 2015). The most convincing examples are that of immunosenescence, which also affects the brain (Cardinali et al., 2008a, Hardeland et al., 2015), as well as the almost exponential increase of hydroxyl radical generation seen in the senescent brain (Poeggeler et al., 1993, Smith et al., 1992).

There is now considerable evidence that, with advancing age, there are increases in sleep disorders such as insomnia and obstructive sleep apnoea. Epidemiological research has shown that more than $50 \%$ of adults above the age of 65 years suffer from some form of a chronic sleep-related complaint (Foley et al., 1995). It is important to distinguish the changes due to aging per se vs. changes due to agingrelated disease and secondary to the use of concomitant medications.

Normative data for sleep variables have been established in a representative population sample of 100 healthy sleepers, aged 19 to 77 years old, based on polysomnography (Mitterling et al., 2015). With increasing age, healthy individuals show changes in their overall sleep duration, in the proportion of time spent in each sleep stage, and in the occurrence of sleep disruptive events. More specifically, in elderly patients sleep efficiency decreases from $87 \%$ to approximately $80 \%$ with a reciprocal increase in sleep onset latency, in the percentage of time spent in stages N1 and N2 (non rapid eye movement, NREM, light sleep stages), and wake after sleep onset. Compared to younger subjects, the elderly shows decrease in total sleep time from approximately $413 \mathrm{~min}$ to approximately $378 \mathrm{~min}$. The number of episodes of apnea or hypopnea episodes per hour and the apnea-hypopnea index is greater in older subjects as well. Notably, reduced oxygenation, as observed in sleep apnoea, is associated with cardiovascular risk (Mitterling et al., 2015). Other age-related decrements include reductions in slow wave sleep (NREM deep sleep; Stage N3) and REM sleep. EEG spectral power analyses of polysomnographic data have confirmed that the elderly have reductions in NREM and REM sleep and a decrease in delta activity (Chellappa et al., 2012, Dijk et al., 1999). In summary, sleep experience becomes increasingly fragmented with advancing age and tends to promote compensatory behaviour such as a greater frequency of daytime naps (Bliwise et al., 2005, Carskadon et al., 1982).

Several studies have shown that sleep disruption is an important contributor to neuropathology. Sleep deprivation (Ooms et al., 2014) or NREM disruption (Ju et al., 2017) have been shown in healthy subjects to increase cerebrospinal fluid (CSF) levels 
of amyloid $\beta(A \beta)_{1-42}$ and $A \beta_{1-40}$, respectively. This reduction was reported to be prevented by a single night of total sleep deprivation (Ooms et al., 2014). In this study, no similar changes were observed in the CSF levels of $A \beta_{1-40}$, or phosphorylated and nonphosphorylated tau protein. As might be expected, no effects of sleep deprivation were detected in amyloid plaques during the short-term period of observation, in accordance with the stability of the aggregates, although correlations of amyloid plaque formation with age were observed.

Similar findings were obtained in mice, in which sleep deprivation caused increases of $A \beta$ peptides in the interstitial fluid of the brain (Kang et al., 2009). Moreover, a relationship between $A \beta$ and wakefulness was established in these animals. Injections of the wakefulness-related neuropeptide orexin led to increases of $A \beta$, whereas an orexin antagonist, almorexant, decreased A $\beta$ levels (Kang et al., 2009). Therefore, although these findings do not yet allow a firm conclusion concerning the effect of sleep deprivation on the development of $A D$, the correlation between $A \beta$ and wakefulness during sleep time should be underlined.

A common mistake is to identify sleep as a central nervous system (CNS)-only phenomenon. In fact, it is a complete physiological program, different from wakefulness, and which comprises two very different physiological states of organs and systems (slow wave, NREM, sleep, and REM sleep). It is as if we live in three different bodies (wakefulness, slow wave sleep and REM sleep) that must necessarily happen in harmony to ensure the state of health (Cardinali, 2017). Some physiological characteristics of the three stages are summarized in Figure 1.

A 76-year-old man (a feasible life expectancy today) who sleeps $8 \mathrm{hr} /$ day has lived 50 years in the physiological state of wakefulness, 20 years in slow wave sleep and 6 years in REM sleep. However, it should be noted that, having modern $24 / 7$ Society a reduction of sleep hours by $25 \%$ over the past 40 years, the above calculation now changes to about 56 years of wakefulness, 15 years of slow wave sleep, and 5 years of REM sleep. We thus live in a private sleep society, in which the sympathetic catabolic configuration of wakefulness has become prevalent at the expense of the parasympathetic anabolic configuration of NREM sleep. In the elderly an age-related reduction in slow wave sleep further adds to the unbalanced of sleep with obvious consequences for health, such as obesity, high blood pressure and diabetes, and neurodegenerative diseases (Fig. 1) (Cardinali, 2017).

\section{Draining of Waste During Sleep}

A process that may considerably contribute to recovery processes in the brain concerns the elimination of waste products during sleep. The conventional view of solute movements in the extracellular space (ECS) of the CNS has been based on diffusion, and the mechanisms modulating the variations in the abundance of products to be eliminated have been sought in the coupling of blood flow and metabolism, processes which are influenced by regulators such as biogenic amines, adenosine, NO, $\mathrm{H}^{+}$, and $\mathrm{K}^{+}$. In the last years, a new interpretation has been put forward, i.e., the glymphatic hypothesis (Iliff et al., 2012, Iliff et al., 2013, Jessen et al., 2015). The term has been coined to describe the active, lymphatic-like movements in the ECS which occur in the brain. It has been suggested that this process, which is normally 
dependent on the activity of lymphatic vessels, can nevertheless take place in the brain, which is devoid of such vessels, because of water exchange. More specifically, it has been hypothesized that solute movement is driven by perivascular astrocytes, which are strongly enriched in aquaporin-4 (AQP4) and by changes in the vascular lumen. AQP4 is predominantly expressed in the end feet of these astrocytes. Water release via AQP4 may be responsible for an actively driven fluid exchange between para-arterial and paravenous spaces, connected by a convective flow through the other parts of the ECS, especially concerning the interstitial fluid. Additionally, it has been assumed that arteriolar pulsations as well as respiration-dependent venular collapse and reinflation may further enhance the flow through occurring in the ECS (Nedergaard, 2013).

Sleep-related variations in cerebral waste products were described (Iliff et al., 2012, Iliff et al., 2013, Jessen et al., 2015). This was of interest, as it also concerned products of relevance in $A D$. The elimination of $A \beta$ peptides has been reported to be considerably enhanced during sleep (Boespflug and Iliff, 2018, Mendelsohn and Larrick, 2013). The concept of glymphatic $A \beta$ clearance has received support from the observation that elimination of injected radiolabelled $A \beta$ peptide was strongly reduced in AQP4 ${ }^{-/}$mice (Iliff et al., 2012). Indeed, the localization of AQP4 in perivascular astrocyte end feet is known to be heavily disturbed in AD (Tang and Yang, 2016, Zeppenfeld et al., 2017). From this point of view, the development and progression of $A D$ might also be due to a failure of $A \beta$ clearance, which is aggravated by sleep disturbance (Yulug et al., 2017). Another AD-related aspect concerns apolipoprotein E clearance from the ECS, sleep deprivation being found to suppress this process (Achariyar et al., 2016). A further finding of potential importance to AD concerned clearance of the tau protein (Iliff et al., 2012). In a subsequent study that included various phosphorylated forms of tau, the AQP4 deficiency aggravated the presence of extracellular tau and neuronal tangle formation via phospho-tau, in a model of traumatic brain injury (Iliff et al., 2014).

The exchange of solutes between the CSF and the interstitial fluid occurs mostly during NREM sleep when the cortical interstitial space increases by more than $60 \%$ and provides a low resistance path for the movement of CSF and interstitial fluid in the brain parenchyma. The contribution of the glymphatic system to the repair function of sleep has been discussed in relation to age-associated deviations from the normal sleep profile, including decreased and delayed CSF penetration of fluid along perivascular pathways and pial surface (Zeppenfeld et al., 2017). Various neurological disease states such as stroke, traumatic brain injury, and $A D$ have been interpreted in terms of the contribution by glymphatic dysfunction (Boespflug and Iliff, 2018).

Despite the attractiveness and explanatory potential of the glymphatic hypothesis, its validity has been questioned (Bacyinski et al., 2017, Smith and Verkman, 2018). A directed convectional flow would require a pressure gradient between CSF and the interstitial fluid, which is, however, rather small (Alperin et al., 2000, Penn et al., 2005) and presumably insufficient for such a mechanism, which would require a pressure difference of several $\mathrm{mm} \mathrm{Hg}$ to overcome the substantial parenchymal hydraulic resistance (Smith and Verkman, 2018). Moreover, studies using a fluorescent dextran subjected to local photobleaching have indicated that an isotropic, nondirected rather 
than a directed solute movement is involved. In addition, after an experimental cardiovascular arrest, the transport of the fluorescent dextran remains unimpaired for several minutes, a finding that indicates that arteriolar pulsations and respirationdependent venular collapses and inflations are relatively unimportant as driving forces for solute transport. Finally, it should be mentioned that experiments using fluorescently labelled $A \beta_{1-40}$ peptide indicated nondirectional diffusion, contrary to the glymphatic concept (Smith and Verkman, 2018).

Regarding the question of sleep in its role of preventing accelerated aging and antagonizing some senescence-related neurological diseases, the decisive findings are those of the sleep-associated increase in clearance of $A \beta$ and other solutes as well as the augmentation of the interstitial space, which certainly facilitates solute movements. Indeed, argumentations concerning the clearance of $A \beta$ should not be restricted to the alternative of directional vs. nondirectional flow, but rather consider the full spectrum of known clearance mechanisms (Tarasoff-Conway et al., 2015). The bulk of evidence support the hypothesis that sleep favours both perivascular and nonperivascular clearance of waste, toxic compounds.

\section{Aging of Sleep as a Social Economic Burden}

The prevalence of primary insomnia varies up to $10 \%$ in the general population and up to $25-30 \%$ in the elderly, for whom the treatment of insomnia is a clear medical necessity. The direct and indirect costs of insomnia represent a substantial social economic burden. Benzodiazepines (BZD) and other BZD receptor agonists (Z-drugs like zolpidem, zaleplon, zopiclone) are the most commonly prescribed drugs for the treatment of insomnia in the elderly (Mandrioli et al., 2010). Several meta-analyses pondering the risks and benefits of these therapeutic options in older patients have reported statistically significant improvements in sleep but have also reported a statistically significant risk of life-threatening adverse events (Winkler et al., 2014). In fact, these drugs are only approved by regulatory agencies for treatment for older adults no more than a few weeks in length due to safety reasons.

$Z$ drugs are used, unlike BZDs, exclusively for the treatment of insomnia and are assumed to have a lower tendency to induce physical dependence and addiction than BZD (Morin and Willett, 2009). However, their safety remains a matter of concern. Adverse effects have been reported in more than $40 \%$ of users of both types of drugs with no difference between BZDs and Z drugs. There is therefore a need for educational programs that warn on these consequences of self-medication and for more elaborate control systems to prevent illegal sale without an archived prescription.

\section{What Melatonin Is}

The light-dark variation in the synthesis of melatonin by pinealocytes is the essential fact that explains the involvement of the pineal gland in the physiology of biological rhythms (Cardinali, 1981). The role of melatonin is twofold: on the one hand it "opens the doors of sleep" by inhibiting the late wake-up activity driven by the SCN (Lewy et al., 2006). In turn, melatonin is the "hormone of darkness", a chemical code of the duration of the night, and has an established in the transmission of light information to the neuroendocrine system. Melatonin represents a "hand" of the biological clock in 
the sense that it responds to signals from the $\mathrm{SCN}$, the temporal variation of the melatonin rhythm indicating the state of the clock, both in terms of phase (time in the internal clock in relation to the external time) and amplitude (Pandi-Perumal et al., 2008).

Melatonin is the prototype of "chronobiotics", drugs used to synchronize and increase the amplitude of circadian rhythms (Cardinali et al., 2008b). A synthetic analogue of melatonin (tasimelteon, Hetlioz ${ }^{\circledR}$, Vanda Pharmaceutical) was approved by the Food and Drug Administration (FDA) in the US in 2013 for use in the circadian sleep disorder with a different rhythm of $24 \mathrm{hr}$ occurring in blind individuals. In Argentina, melatonin was introduced as a drug for insomnia in 1995 and there are today melatonin analogues used for this purpose in the USA (ramelteon, Rozerem ${ }^{R}$, Takeda) as well as for the treatment of depression (agomelatine, Valdoxan ${ }^{R}$; Servier) approved by the European Medicines Agency (EMA) in Europe. In 2007 a slow release form of melatonin ( $2 \mathrm{mg}$, Circadin $^{\circledR}$, Neurim) was approved as a medicament by EMA.

Around 30 years ago, an observation of Aaron Lerner, the discoverer of melatonin, started to rise interest: the drowsiness produced by the melatonin when Lerner administered it to himself and to his patients (Lerner and Nordlund, 1978). At that time, our laboratory in Buenos Aires had acquired considerable experience in the determination of receptors by methods of high affinity binding and as soon as a tritiated melatonin of specific high activity $(30 \mathrm{Ci} / \mathrm{mmol})$ was introduced in the market, we shortly identified the brain receptors for melatonin in areas of the bovine and rat brains (Cardinali et al., 1978, Cardinali et al., 1979). In other studies, we verified changes in receptor concentration correlated with circulating levels of melatonin and ambient light status (Vacas and Cardinali, 1979). By 1983, there were significant advances in autoradiographic and immunohistochemical receptor detection techniques by the introduction of an iodinated ligand of melatonin, 2-125/-melatonin, and the knowledge in the field of melatonin receptors exploded, culminating with receptor cloning in the 1990s.

Based on their kinetic properties, specificity and localization different melatonin receptors have been identified in both the CNS and the periphery. The $\mathrm{MT}_{1}$ and $\mathrm{MT}_{2}$ receptors (Dubocovich et al., 2010), all belonging to the membrane receptor superfamily associated with $\mathrm{G}$ proteins, have been cloned. These receptors mediate melatonin inhibition of adenylate cyclase (and in the case of the $\mathrm{MT}_{2}$ receptor, guanylate cyclase) and participate in the action of melatonin on the phase and amplitude of the circadian rhythms. Due to its liposolubility melatonin crosses the membranes and is associated with cytoplasmic proteins such as calmodulin and tubulin, causing important changes in the cytoskeleton (Benitez-King, 2006). Melatonin also accesses the cell nucleus where receptor sites have also been described. The nuclear receptor for melatonin belongs to the superfamily of orphan receptors RZR / ROR that participate in immunomodulation (Hardeland et al., 2011).

Both in the cytoplasm and in the cell nucleus melatonin has important antioxidant and scavenger effects on free radicals, which are largely independent on receptors (Manchester et al., 2015). These effects are exerted in three ways: (a) Melatonin has scavenger activity. (b) Melatonin is metabolized to compounds with high antioxidant activity. (c) Melatonin is an indirect antioxidant, stimulating the synthesis of 
antioxidant enzymes and inhibiting that of prooxidant enzymes. Indeed, almost every cell in the human body contains melatonin, in quantities much higher than that circulating in blood derived from the pineal gland. For reasons that remain unexplained, intracellular melatonin does not get the extracellular space. To modify intracellular melatonin levels, doses much higher than those employed as a chronobiotic are needed. Several antiapoptotic and cytoprotective effects of melatonin are exerted under conditions of ischemia (not related to free radicals) and can be attributable to a mitochondrial membrane stabilizing activity (AcuñaCastroviejo et al., 2012). Thus, melatonin has the potential to be an effective tool for healthy aging.

\section{Melatonin and BZD Interaction}

BZD receptor agonists are the most commonly prescribed drugs for the treatment of insomnia in the elderly. The BZD are a group of compounds that exert their therapeutic effect on sleep through allosteric modulation of the GABAA receptor complex. BZD have broad inhibitory effects on brain functions, including promoting sleep, anxiolysis, anticonvulsant effects, cognitive and motor impairment, and reinforcing effects (Rosini and Dogra, 2015). In addition, significant adverse effects such as cognitive and psychomotor impairment, next day hangover, rebound insomnia, anterograde amnesia, and dependence have been documented, thus making the use of BZD for prolonged treatment of insomnia highly controversial. " $Z$ drugs" are a group of agents that are not part of the chemical class BZD but act through the same mechanism, the allosteric modulation of the $\mathrm{GABA}_{\mathrm{A}}$ receptor. Generally, $\mathrm{Z}$ drug hypnotics, although effective in reducing sleep latency, are only moderately effective in increasing sleep efficiency (Rosini and Dogra, 2015).

Advisement against long-acting hypnotic BZD and Z drug use and recommendations to employ them for the shortest time possible in older patients (no more than 2-3 weeks of treatment) are common nowadays. For example, the American Geriatrics Society has recently updated its list of inappropriate medications for older patients and advised physicians to "avoid benzodiazepines (any type) for treatment of insomnia, agitation, or delirium" (2012). Unlike BZD, Z drugs are used, exclusively for the treatment of insomnia and are supposed to have a reduced risk for inducing physical dependence and addiction than BZD. However, adverse effects have been reported in more than $40 \%$ of users of both BZD and $Z$ drugs.

Health authorities in Europe are increasingly initiating policies and recommendations to reduce the consumption of BZD and Z drugs. However, the campaigns have not been generally successful, despite national guidelines and recommendations, and the use of these drugs has continued to increase. The clearer strategy to reduce chronic BZD use is to reduce medication; abrupt cessation can only be justified if a serious adverse effect occurs during treatment. There is no clear evidence regarding the optimal rate of taper, and times vary from 4 weeks to several months.

Thirty years ago, we demonstrated the interaction of melatonin with central BZD receptors and in 1997 we published the first demonstration of the reduction of BZD consumption in melatonin-treated elderly subjects (Fainstein et al., 1997). As mentioned, in 2007 a sustained release form of $2 \mathrm{mg}$ of melatonin was approved by 
the EMA for the treatment of insomnia in elderly people. The fact that melatonin does not show evidence of dependency, isolation, rebound insomnia or negative influence on alertness during the day was emphasized by EMA for melatonin as well as by the FDA for the melatonin analogues ramelteon and tasimelteon.

Melatonin competes with BZD and Z drugs at their site of action. A facilitator role of melatonin on GABA neurotransmission explains the anxiolytic, antihyperalgesic and antinociceptive effects of melatonergic agents (Cardinali et al., 2016). Several clinical studies now support the efficacy of melatonin to reduce BZD use in chronically treated patients (Baandrup et al., 2016a, Baandrup et al., 2016b, Cardinali et al., 2016). In a pharmaco-epidemiologic study aimed to evaluate the impact of anti-BZD / Z drugs campaigns and the availability of alternative pharmacotherapy (melatonin) on the consumption of BZD and $Z$ drugs in several European countries, the results indicated that campaigns failed unless they were associated with the availability of melatonin in the market (Clay et al., 2013). Melatonin has thus become the treatment of choice for the preservation of slow wave sleep and healthy aging in the elderly.

\section{Melatonin in AD}

Cross-sectional studies reveal that sleep disturbances are associated with memory and cognitive impairment (Ooms and Ju, 2016). A severe disruption of the circadian timing system occurs in $A D$ as indicated by alterations in numerous bodily rhythms such as body temperature, glucocorticoids and/or plasma melatonin. The internal desynchronization of rhythms is significant in $A D$ patients. One emerging symptom is "sundowning", a chronobiological phenomenon observed in AD patients in conjunction with sleep-wake disturbances (Ooms and Ju, 2016). Sundowning includes symptoms such as disorganized thinking, reductions in the ability to maintain attention to external stimuli, agitation, wandering and perceptual and emotional disturbances, all appearing in the late afternoon or early evening. Chronotherapeutic interventions such as exposure to bright light and timed administration of melatonin in selected circadian phases alleviated sundowning symptoms and improved sleep-wake patterns of $A D$ patients (Cardinali et al., 2002, Riemersma-van der Lek RF et al., 2008).

CSF melatonin levels decrease even in preclinical stages of $A D$ when the patients do not manifest any cognitive impairment, suggesting that the reduction in CSF melatonin may be an early trigger and marker for $A D$ (Liu et al., 1999). Although it is not known whether the relative melatonin deficiency is either a consequence or a cause of neurodegeneration, it seems clear that the loss in melatonin aggravates the disease and that early circadian disruption can be an important deficit to be considered. Significant differences were observed in melatonin levels between mild cognitive impairment $(\mathrm{MCl})$ and $A D$ patients with a negative correlation between neuropsychological assessment of dementia and melatonin levels (Sirin et al., 2015).

$\mathrm{MCl}$ is diagnosed in those who have an objective and measurable deficit in cognitive functions, but with a preservation of daily activities. The estimates of annual conversion rates to dementia vary across studies but may be as high $10-15 \%, \mathrm{MCl}$ representing a clinically important stage for identifying and treating individuals at risk (Allan et al., 2017). Indeed, the degenerative process in AD brain starts 20-30 years 
before the clinical onset of the disease. During this phase, plaques and tangles loads increase and at a certain threshold, the first symptom appears.

Two recent meta-analyses endorsed the view that melatonin therapy is effective in improving sleep in patients with dementia (Xu et al., 2015, Zhang et al., 2016). Moreover, the melatonergic agonist ramelteon was reported as effective to treat delirium, an acute state of mental confusion that can lead to many adverse sequelae in intensive care unit elder patients (Furuya et al., 2012).

Whether melatonin has any value in treating fully developed AD remains uncertain. It must be noted that one of the problems with AD patients with fully developed pathology is the heterogeneity of the group examined. Moreover, the reduced hippocampal expression of $\mathrm{MT}_{2}$ melatonin receptors in $\mathrm{AD}$ patients and of $\mathrm{MT}_{1}$ receptors in the circadian apparatus at later stages the disease may explain why melatonin treatment is less effective or erratic at this stage (Wu et al., 2007).

Mild cognitive impairment $(\mathrm{MCl})$ is diagnosed in those who have an objective and measurable deficit in cognitive functions, but with a preservation of daily activities. The estimates of annual conversion rates to dementia vary across studies but may be as high $10-15 \%, \mathrm{MCl}$ representing a clinically important stage for identifying and treating individuals at risk. Indeed, the degenerative process in AD brain starts 20-30 years before the clinical onset of the disease. During this phase, plaques and tangles loads increase and at a certain threshold the first symptom appears (Cespon et al., 2018).

An analysis of published data of the use of melatonin in the early stages of cognitive decline consistently showed that administration of melatonin, every night before retiring, improves the quality of sleep and cognitive performance in this phase of the disease (Cardinali et al., 2014). In our Laboratory, we carried out a retrospective analysis of 25 patients with $\mathrm{MCl}$ who in the past three years had received a daily dose of 3-9 mg of melatonin along with their usual medication. Compared to an untreated group melatonin treated patients significantly improved cognitive and emotional performance and quality of sleep / wake rhythm (Furio et al., 2007). We also reported another series of 96 outpatients with a diagnosis of minimal cognitive impairment, 61 of who had received 3-24 mg of melatonin daily for 15 to 60 months. Patients treated with melatonin showed a significantly better performance in various neuropsychological tests. They also had lower scores in the Beck Depression Inventory concomitantly with improvement in the quality of sleep and wakefulness (Cardinali et al., 2012). Therefore, melatonin treatment can be effective in the early stages of neurodegenerative disease.

The mechanisms accounting for the therapeutic effect of melatonin in $\mathrm{MCl}$ patients remain to be defined. Melatonin treatment mainly promotes slow wave sleep in the elderly and can be beneficial in $\mathrm{MCl}$ by augmenting the restorative phases of sleep, including the augmented secretion of $\mathrm{GH}$ and neurotrophins and the functioning of the glymphatic system. The antioxidant, mitochondrial and anti-amyloidogenic effects of melatonin may be a strategy for interfering with the onset of the disease (Cardinali et al., 2014) (Fig). 
Owing to the multifactorial nature of $A D$ pathogenesis, polypharmacy with drugs that target heterogeneous pathophysiological pathways must be considered. A novel pharmacological treatment paradigm (the " $\mathrm{M}$ " Drugs) was proposed involving the use of melatonin, minocycline, modafinil, and memantine (Daulatzai, 2016). Minocycline is neuroprotective; it reduces neuroinflammation and CNS pathology and prevents cell death. Modafinil, a wake-promoting agent, improves global mental status, hippocampal neurogenesis, attention, and cognition. Memantine is an NMDA receptor antagonist and is approved for the management of moderate-to-severe AD. This sort of multi-drug strategies, if safe and well-tolerated in combination, may provide a comprehensive and pragmatic means to combat multiple pathological targets and ameliorate cognitive dysfunction in AD. Therefore, when melatonin treatment begins can be decisive for a final response. Double-blind multicentre studies are needed to further explore and investigate the potential and usefulness of melatonin to slow down disease progression when taken at the early stage of the neurodegenerative disease.

\section{Conclusion}

Melatonin is widely used as a food supplement, dietetic product, and drug in many countries worldwide. The European Food Safety Authority (EFSA) has allowed the health claim that melatonin reduces sleep onset latency $(2010,2011)$. This allows the introduction of melatonin as food in improving "sleep-wake cycle regulation", "relaxation" and "sleep patterns". Melatonin, melatonin-rich food and bioextracts therefrom are now developed to serve as nutritional supplements, dietetic products, and drugs. The target group was defined by the EFSA to be the general population and as such those extracts can be marketed in the all EU countries.

As discussed above, melatonin combines two properties for application in human medicine: chronobiotic and cytoprotection. As mentioned, almost every cell in the human body contains melatonin, in quantities much higher than that circulating in blood derived from the pineal gland. To modify intracellular melatonin levels, doses much higher than those employed as a chronobiotic are need (i.e. in the 40-100 $\mathrm{mg} /$ day range). The amazing phylogenetic conservation of melatonin strongly suggests that their cytoprotective functions are of relevance for cell function. There is an increasing scientific interest on this point. A Medline search of studies that relate melatonin to antioxidant and cytoprotective activity indicates the existence of more than 3,500 scientific publications in the past 5 years.

Different studies indicate that, as in animal tissues, melatonin also reduces oxidative stress in plants. Indeed, its discovery in plants two decades ago has opened an emerging field of research that has made substantial progress in understanding the actions of melatonin that contribute to the ecological success of plants.

Overexpression of melatonin in plants facilitates the germination of seeds and improves plant development and maturation of both root and tissue above the ground, protecting plants from abiotic and biotic stress (Arnao and Hernandez-Ruiz, 2015, Erland et al., 2015, Tan et al., 2014). Thus, melatonin presence in plants has implications not only for plant growth and crop yield, but also in terms of human and animal nutrition. When plant products containing melatonin are consumed, the compound is easily absorbed and exerts its functions at the cellular level. Therefore, in 
animals and plants, melatonin is a highly useful molecule that neutralizes pathophysiological processes that compromise a healthy lifestyle.

Enrichment in melatonin in food seems necessary to achieve the amounts that provided effective cytoprotection. Thus, one area of interest is the development of functional foods with high levels of melatonin. Two are the possible strategies to achieve this:

1. to develop genetically engineered soybean varieties or rice or tomatoes that overexpress melatonin. This would have the dual purpose of responding to the medical problem (getting a dietary supplement that provides $30-50 \mathrm{mg}$ of melatonin per serving) and application development in agriculture facilitating the adaptation of plants to hostile environments.

2. to enrich foods with added melatonin (e.g. soy milk) to obtain a dietary supplement that provides high amounts of melatonin per serving.

In parallel, toxicity of long term melatonin use should be evaluated. From animal studies it is clear that a number of potentially useful effects of melatonin, like those in neurodegenerative disorders or in the metabolic syndrome, need high doses of melatonin to become apparent. If one expects melatonin to be effective in improving health, especially in aged people, it is likely that the low doses of melatonin commonly employed (less than $10 \mathrm{mg} /$ day) so far are not very beneficial.

Published reports indicate that melatonin is a safe drug with low toxicity in the short term (Fulia et al., 2001, Gitto et al., 2001, Gitto et al., 2004a, Gitto et al., 2004b). In experimental studies where melatonin was given in doses of $200 \mathrm{mg} / \mathrm{kg}$ to pregnant rats throughout pregnancy or $800 \mathrm{mg} / \mathrm{kg}$ body weight in mice, no toxicity or death was observed (Barchas et al., 1967) (Jahnke et al., 1999). In clinical studies, high doses of melatonin were given to patients with hyperpigmented skin (1 g melatonin/day for one month) (Nordlund and Lerner, 1977) where the only side effect was drowsiness. Parkinsonian patients were successfully treated with melatonin administered intravenously in doses between 0.25 and $1.25 \mathrm{mg} / \mathrm{kg}$ of body weight without any relevant side effect (Anton-Tay et al., 1971).

In the treatment of amyotrophic lateral sclerosis patients received either $60 \mathrm{mg} /$ day orally for up to 13 months (Jacob et al., 2002) or enteral doses of $300 \mathrm{mg} /$ day for up to 2 years (Weishaupt et al., 2006). In children with muscular dystrophy, administration of $70 \mathrm{mg} /$ day melatonin reduced levels of inflammatory cytokines and lipid peroxidation (Chahbouni et al., 2011). In healthy individuals doses up to $80 \mathrm{mg}$ melatonin per hour for $4 \mathrm{~h}$ produced no untoward effects (Waldhauser et al., 1990). Healthy women in a dose of 300 mg melatonin / day for 4 months did not produce negative side effects(Silman, 1993). A controlled in 50 patients referred for liver surgery clinical trial found that a single enteral preoperative dose of $50 \mathrm{mg} / \mathrm{kg}$ of melatonin (i.e., equivalent to $3 \mathrm{~g}$ for an adult of $60 \mathrm{~kg}$ ) was safe and well tolerated (Nickkholgh et al., 2011). Generally, the rarely observed adverse events associated with melatonin intake include headaches, dizziness, nausea, and drowsiness. In two dose escalation studies of melatonin in healthy volunteers the tolerability and pharmacokinetics of up to $100 \mathrm{mg}$ oral doses of melatonin were assessed with no adverse effects detected (Andersen et al., 2016, Galley et al., 2014)[23;24]. 
The approach used to document melatonin efficacy in treatment and prevention of osteoporosis by an early development budget impact model can be fundamental to urge health authorities in this respect (Bondi et al., 2015). In the U.S.A. the economic impact of osteoporosis is estimated to be $\$ 23$ billion by 2025. Current drug therapies either decrease bone resorption (e.g., bisphosphonates) or stimulate bone formation (e.g., teriparatide). Melatonin may be a potential treatment option because research has shown it impacts bone metabolism by promoting osteoblast differentiation and activity and by suppressing osteoclast differentiation and activity. Bondi et al.'s paper clearly demonstrated in a 1-year budget impact model with a hypothetical plan population of 1 million that the addition of melatonin to a formulary will provide substantial cost offsets to the payer in the treatment and prevention of osteoporosis (Bondi et al., 2015). This sort of arguments could persuade Health authorities to support basis studies of melatonin as a nutraceutical. 


\section{References}

Achariyar TM, Li B, Peng W, Verghese PB, Shi Y, McConnell E, Benraiss A, Kasper T, Song W, Takano T, Holtzman DM, Nedergaard M, Deane R 2016. Glymphatic distribution of CSF-derived apoE into brain is isoform specific and suppressed during sleep deprivation. Mol Neurodegener. 11:74.

Acuña-Castroviejo D, Carretero M, Doerrier C, Lopez LC, Garcia-Corzo L, Tresguerres JA, Escames $\mathrm{G}$ 2012. Melatonin protects lung mitochondria from aging. Age (Dordr ). 34:681-692.

Allan CL, Behrman S, Ebmeier KP, Valkanova V 2017. Diagnosing early cognitive decline-When, how and for whom? Maturitas. 96:103-108.

Alperin NJ, Lee SH, Loth F, Raksin PB, Lichtor T 2000. MR-Intracranial pressure (ICP): a method to measure intracranial elastance and pressure noninvasively by means of $M R$ imaging: baboon and human study. Radiology. 217:877-885.

American Geriatrics Society 2012. American Geriatrics Society updated Beers Criteria for potentially inappropriate medication use in older adults. J Am Geriatr Soc. 60:616631.

Andersen LP, Werner MU, Rosenkilde MM, Fenger AQ, Petersen MC, Rosenberg J, Gogenur I 2016. Pharmacokinetics of high-dose intravenous melatonin in humans. J Clin Pharmacol. 56:324-329.

Anton-Tay F, Diaz JL, Fernandez-Guardiola A 1971. On the effect of melatonin upon human brain. Its possible therapeutic implications. Life Sci I. 10:841-850.

Arnao MB, Hernandez-Ruiz J 2015. Functions of melatonin in plants: a review. J Pineal Res. 59:133-150.

Baandrup L, Fasmer OB, Glenthoj BY, Jennum PJ 2016a. Circadian rest-activity rhythms during benzodiazepine tapering covered by melatonin versus placebo add-on: data derived from a randomized clinical trial. BMC Psychiatry. 16:348.

Baandrup L, Glenthoj BY, Jennum PJ 2016b. Objective and subjective sleep quality: Melatonin versus placebo add-on treatment in patients with schizophrenia or bipolar disorder withdrawing from long-term benzodiazepine use. Psychiatry Res. 240:163169.

Bacyinski A, Xu M, Wang W, Hu J 2017. The paravascular pathway for brain waste clearance: current understanding, significance and controversy. Front Neuroanat. 11:101. 
Barchas J, DaCosta F, Spector S 1967. Acute pharmacology of melatonin. Nature. 214:919-920.

Benitez-King G 2006. Melatonin as a cytoskeletal modulator: implications for cell physiology and disease. J Pineal Res. 40:1-9.

Bhatti JS, Kumar S, Vijayan M, Bhatti GK, Reddy PH 2017. Therapeutic strategies for mitochondrial dysfunction and oxidative stress in age-related metabolic disorders. Prog Mol Biol Transl Sci. 146:13-46.

Bliwise DL, Ansari FP, Straight LB, Parker KP 2005. Age changes in timing and 24-hour distribution of self-reported sleep. Am J Geriatr Psychiatry. 13:1077-1082.

Boespflug EL, Iliff JJ 2018. The emerging relationship between interstitial fluidcerebrospinal fluid exchange, amyloid-beta, and sleep. Biol Psychiatry. 83:328-336.

Bondi CD, Khainar R, Karnal KM, Witt-Enderby P 2015. An early development budget impact model for the use of melatonin in the treatment and prevention of osteoporosis. Clin Pharmacol Biopharm. 4:doi.org/10.4172/2167-065X.1000132.

Branger P, Arenaza-Urquijo EM, Tomadesso C, Mezenge F, Andre C, de FR, Mutlu J, de LS, V, Eustache F, Chetelat G, Rauchs G 2016. Relationships between sleep quality and brain volume, metabolism, and amyloid deposition in late adulthood. Neurobiol Aging. 41:107-114.

Burkle A 2002. In memoriam Bernard Strehler--genomic instability in ageing: a persistent challenge. Mech Ageing Dev. 123:899-906.

Cardinali DP 1981. Melatonin. A mammalian pineal hormone. Endocr Rev. 2:327-346.

Cardinali DP 2017. Autonomic nervous system. Basic and clinical aspects, Switzerland: Springer International Publishing.

Cardinali DP, Brusco LI, Liberczuk C, Furio AM 2002. The use of melatonin in Alzheimer's disease. Neuro Endocrinol Lett. 23 Suppl 1:20-23.

Cardinali DP, Esquifino Al, Srinivasan V, Pandi-Perumal SR 2008a. Melatonin and the immune system in aging. Neuroimmunomodulation. 15:272-278.

Cardinali DP, Golombek D, Rosenstein RE, Brusco LI, Vigo DE 2016. Assessing the efficacy of melatonin to curtail benzodiazepine/ Z drug abuse. Pharmacol Res. 109:1223.

Cardinali DP, Pandi-Perumal SR, Srinivasan V, Spence DW, Trakht I 2008b. Therapeutic potential of melatonin agonists. Expert Review Endocrinol Metab. 3 (2):269-279.

Cardinali DP, Vacas MI, Boyer EE 1978. High affinity binding of melatonin in bovine medial basal hypothalamus. IRCS Med Sci. 6:357. 
Cardinali DP, Vacas MI, Boyer EE 1979. Specific binding of melatonin in bovine brain. Endocrinology. 105:437-441.

Cardinali DP, Vigo DE, Olivar N, Vidal MF, Brusco LI 2014. Melatonin therapy in patients with Alzheimer's disease. Antioxidants. 3:245-277.

Cardinali DP, Vigo DE, Olivar N, Vidal MF, Furio AM, Brusco LI 2012. Therapeutic application of melatonin in mild cognitive impairment. Amer J Neurodegenerative Dis. 1:280-291.

Carskadon MA, Brown ED, Dement WC 1982. Sleep fragmentation in the elderly: relationship to daytime sleep tendency. Neurobiol Aging. 3:321-327.

Cespon J, Miniussi C, Pellicciari MC 2018. Interventional programmes to improve cognition during healthy and pathological ageing: Cortical modulations and evidence for brain plasticity. Ageing Res Rev. 43:81-98.

Chahbouni M, Escames G, Lopez LC, Sevilla B, Doerrier C, Muñoz-Hoyos A, MolinaCarballo A, Acuña-Castroviejo D 2011. Melatonin treatment counteracts the hyperoxidative status in erythrocytes of patients suffering from Duchenne muscular dystrophy. Clin Biochem. 44:853-858.

Chellappa SL, Munch M, Knoblauch V, Cajochen C 2012. Age effects on spectral electroencephalogram activity prior to dream recall. J Sleep Res. 21:247-256.

Cirelli C, Tononi G 2008. Is sleep essential? PLoS Biol. 6:e216.

Clay E, Falissard B, Moore N, Toumi M 2013. Contribution of prolonged-release melatonin and anti-benzodiazepine campaigns to the reduction of benzodiazepine and Z-drugs consumption in nine European countries. Eur J Clin Pharmacol. 69:1-10.

Daulatzai MA 2016. Pharmacotherpy and Alzheimer's Disease: The M-drugs (melatonin, minocycline, modafinil, and memantine) approach. Curr Pharm Des. 22:2411-2430.

Dijk DJ, Duffy JF, Riel E, Shanahan TL, Czeisler CA 1999. Ageing and the circadian and homeostatic regulation of human sleep during forced desynchrony of rest, melatonin and temperature rhythms. J Physiol. 516 ( Pt 2):611-627.

Dubocovich ML, Delagrange P, Krause DN, Sugden D, Cardinali DP, Olcese J 2010. International Union of Basic and Clinical Pharmacology. LXXV. Nomenclature, classification, and pharmacology of $\mathrm{G}$ protein-coupled melatonin receptors. Pharmacol Rev. 62:343-380.

Duffy JF, Zitting KM, Chinoy ED 2015. Aging and circadian rhythms. Sleep Med Clin. 10:423-434.

EFSA Panel on Dietetic Products, Nutrition and Allergies (NDA). Scientific Opinion on the substantiation of health claims related to melatonin and alleviation of subjective 
feelings of jet lag (ID 1953), and reduction of sleep onset latency, and improvement of sleep quality (ID 1953) pursuant to Article 13 of Regulation (EC) No 1924/20061. EFSA J., 2010, 8, 1461.

EFSA Panel on Dietetic Products, Nutrition and Allergies (NDA). Scientific Opinion on the substantiation of a health claim related to melatonin and reduction of sleep onset latency (ID 1698; 1780, 4080) pursuant to Article 13 of Regulation (EC) No 1924/2006. EFSA J. 9, 2241.

Erland LA, Murch SJ, Reiter RJ, Saxena PK 2015. A new balancing act: The many roles of melatonin and serotonin in plant growth and development. Plant Signal Behav. 10:e1096469.

Fainstein I, Bonetto A, Brusco LI, Cardinali DP 1997. Effects of melatonin in elderly patients with sleep disturbance. A pilot study. Curr Ther Res. 58:990-1000.

Foley DJ, Monjan AA, Brown SL, Simonsick EM, Wallace RB, Blazer DG 1995. Sleep complaints among elderly persons: an epidemiologic study of three communities. Sleep. 18:425-432.

Fulia F, Gitto E, Cuzzocrea S, Reiter RJ, Dugo L, Gitto P, Barberi S, Cordaro S, Barberi I 2001. Increased levels of malondialdehyde and nitrite/nitrate in the blood of asphyxiated newborns: reduction by melatonin. J Pineal Res. 31:343-349.

Furio AM, Brusco LI, Cardinali DP 2007. Possible therapeutic value of melatonin in mild cognitive impairment. A retrospective study. J Pineal Res. 43 (4):404-409.

Furuya M, Miyaoka T, Yasuda H, Yamashita S, Tanaka I, Otsuka S, Wake R, Horiguchi J 2012. Marked improvement in delirium with ramelteon: five case reports.

Psychogeriatrics. 12:259-262.

Galley HF, Lowes DA, Allen L, Cameron G, Aucott LS, Webster NR 2014. Melatonin as a potential therapy for sepsis: a phase I dose escalation study and an ex vivo whole blood model under conditions of sepsis. J Pineal Res. 56:427-438.

Gitto E, Reiter RJ, Cordaro SP, La RM, Chiurazzi P, Trimarchi G, Gitto P, Calabro MP, Barberi I 2004a. Oxidative and inflammatory parameters in respiratory distress syndrome of preterm newborns: beneficial effects of melatonin. Am J Perinatol. 21:209-216.

Gitto E, Romeo C, Reiter RJ, Impellizzeri P, Pesce S, Basile M, Antonuccio P, Trimarchi G, Gentile C, Barberi I, Zuccarello B 2004b. Melatonin reduces oxidative stress in surgical neonates. J Pediatr Surg. 39:184-189.

Gitto E, Tan DX, Reiter RJ, Karbownik M, Manchester LC, Cuzzocrea S, Fulia F, Barberi I 2001. Individual and synergistic antioxidative actions of melatonin: studies with vitamin $\mathrm{E}$, vitamin $\mathrm{C}$, glutathione and desferrioxamine (desferoxamine) in rat liver homogenates. J Pharm Pharmacol. 53:1393-1401. 
Gubin DG, Weinert D, Bolotnova TV 2016. Age-dependent changes of the temporal order - causes and treatment. Curr Aging Sci. 9:14-25

Hardeland R 2015. Melatonin and circadian oscillators in aging--a dynamic approach to the multiply connected players. Interdiscip Top Gerontol. 40:128-140.

Hardeland R, Cardinali DP, Brown GM, Pandi-Perumal SR 2015. Melatonin and brain inflammaging. Prog Neurobiol. 127-128:46-63.

Hardeland R, Cardinali DP, Srinivasan V, Spence DW, Brown GM, Pandi-Perumal SR 2011. Melatonin--a pleiotropic, orchestrating regulator molecule. Prog Neurobiol. 93:350-384.

Harman D 1981. The aging process. Proc Natl Acad Sci U S A. 78:7124-7128.

Iliff JJ, Chen MJ, Plog BA, Zeppenfeld DM, Soltero M, Yang L, Singh I, Deane R, Nedergaard M 2014. Impairment of glymphatic pathway function promotes tau pathology after traumatic brain injury. J Neurosci. 34:16180-16193.

Iliff JJ, Lee H, Yu M, Feng T, Logan J, Nedergaard M, Benveniste H 2013. Brain-wide pathway for waste clearance captured by contrast-enhanced MRI. J Clin Invest. 123:1299-1309.

Iliff JJ, Wang M, Liao Y, Plogg BA, Peng W, Gundersen GA, Benveniste H, Vates GE, Deane R, Goldman SA, Nagelhus EA, Nedergaard M 2012. A paravascular pathway facilitates CSF flow through the brain parenchyma and the clearance of interstitial solutes, including amyloid beta. Sci Transl Med. 4:147ra111.

Jacob S, Poeggeler B, Weishaupt JH, Siren AL, Hardeland R, Bahr M, Ehrenreich H 2002. Melatonin as a candidate compound for neuroprotection in amyotrophic lateral sclerosis (ALS): high tolerability of daily oral melatonin administration in ALS patients. J Pineal Res. 33:186-187.

Jahnke G, Marr M, Myers C, Wilson R, Travlos G, Price C 1999. Maternal and developmental toxicity evaluation of melatonin administered orally to pregnant Sprague-Dawley rats. Toxicol Sci. 50:271-279.

Jessen NA, Munk AS, Lundgaard I, Nedergaard M 2015. The Glymphatic System: A Beginner's Guide. Neurochem Res. 40:2583-2599.

Ju YS, Ooms SJ, Sutphen C, Macauley SL, Zangrilli MA, Jerome G, Fagan AM, Mignot E, Zempel JM, Claassen JAHR, Holtzman DM 2017. Slow wave sleep disruption increases cerebrospinal fluid amyloid-beta levels. Brain. 140:2104-2111.

Kang JE, Lim MM, Bateman RJ, Lee JJ, Smyth LP, Cirrito JR, Fujiki N, Nishino S, Holtzman DM 2009. Amyloid-beta dynamics are regulated by orexin and the sleep-wake cycle.

Science. 326:1005-1007. 
Lerner AB, Nordlund JJ 1978. Melatonin: clinical pharmacology. J Neural Transm Suppl. 339-347.

Lewy AJ, Emens J, Jackman A, Yuhas K 2006. Circadian uses of melatonin in humans. Chronobiol Int. 23:403-412.

Liu RY, Zhou JN, van HJ, Hofman MA, Swaab DF 1999. Decreased melatonin levels in postmortem cerebrospinal fluid in relation to aging, Alzheimer's disease, and apolipoprotein E-epsilon4/4 genotype. J Clin Endocrinol Metab. 84:323-327.

Manchester LC, Coto-Montes A, Boga JA, Andersen LP, Zhou Z, Galano A, Vriend J, Tan DX, Reiter RJ 2015. Melatonin: an ancient molecule that makes oxygen metabolically tolerable. J Pineal Res. 59:403-419.

Mandrioli R, Mercolini L, Raggi MA 2010. Metabolism of benzodiazepine and nonbenzodiazepine anxiolytic-hypnotic drugs: an analytical point of view. Curr Drug Metab. 11:815-829.

Mazzotti DR, Guindalini C, Moraes WA, Andersen ML, Cendoroglo MS, Ramos LR, Tufik $S$ 2014. Human longevity is associated with regular sleep patterns, maintenance of slow wave sleep, and favorable lipid profile. Front Aging Neurosci. 6:134.

Mendelsohn AR, Larrick JW 2013. Sleep facilitates clearance of metabolites from the brain: glymphatic function in aging and neurodegenerative diseases. Rejuvenation Res. 16:518-523.

Mitterling T, Hogl B, Schonwald SV, Hackner H, Gabelia D, Biermayr M, Frauscher B 2015. Sleep and respiration in 100 healthy caucasian sleepers--a polysomnographic study according to American Academy of Sleep Medicine Standards. Sleep. 38:867-875.

Morin AK, Willett K 2009. The role of eszopiclone in the treatment of insomnia. Adv Ther. 26:500-518.

Nedergaard M 2013. Neuroscience. Garbage truck of the brain. Science. 340:15291530 .

Nickkholgh A, Schneider H, Sobirey M, Venetz WP, Hinz U, Pelzl IH, Gotthardt DN, Cekauskas A, Manikas M, Mikalauskas S, Mikalauskene L, Bruns H, Zorn M, Weigand MA, Buchler MW, Schemmer P 2011. The use of high-dose melatonin in liver resection is safe: first clinical experience. J Pineal Res. 50:381-388.

Nordlund JJ, Lerner AB 1977. The effects of oral melatonin on skin color and on the release of pituitary hormones. J Clin Endocrinol Metab. 45:768-774.

Ooms S, Ju YE 2016. Treatment of Sleep Disorders in Dementia. Curr Treat Options Neurol. 18:40. 
Ooms S, Overeem S, Besse K, Rikkert MO, Verbeek M, Claassen JA 2014. Effect of 1 night of total sleep deprivation on cerebrospinal fluid beta-amyloid 42 in healthy middle-aged men: a randomized clinical trial. JAMA Neurol. 71:971-977.

Pandi-Perumal SR, Trakht I, Srinivasan V, Spence DW, Maestroni GJM, Zisapel N, Cardinali DP 2008. Physiological effects of melatonin: role of melatonin receptors and signal transduction pathways. Progress in Neurobiology. 185:335-353.

Penn RD, Lee MC, Linninger AA, Miesel K, Lu SN, Stylos L 2005. Pressure gradients in the brain in an experimental model of hydrocephalus. J Neurosurg. 102:1069-1075.

Poeggeler B, Reiter RJ, Tan DX, Chen LD, Manchester LC 1993. Melatonin, hydroxyl radical-mediated oxidative damage, and aging: a hypothesis. J Pineal Res. 14:151-168.

Riemersma-van der Lek RF, Swaab DF, Twisk J, Hol EM, Hoogendijk WJ, Van Someren EJ 2008. Effect of bright light and melatonin on cognitive and noncognitive function in elderly residents of group care facilities: a randomized controlled trial. JAMA. 299:2642-2655.

Rosini JM, Dogra P 2015. Pharmacology for insomnia: consider the options. Nursing. 45:38-45.

Silman RE 1993. Melatonin: a contraceptive for the nineties. Eur J Obstet Gynecol Reprod Biol. 49:3-9.

Sirin FB, Kumbul DD, Vural H, Eren I, Inanli I, Sutcu R, Delibas N 2015. Plasma 8isoPGF $2 \alpha$ and serum melatonin levels in patients with minimal cognitive impairment and Alzheimer disease. Turk J Med Sci. 45:1073-1077.

Smith AJ, Verkman AS 2018. The "glymphatic" mechanism for solute clearance in Alzheimer's disease: game changer or unproven speculation? FASEB J. 32:543-551.

Smith CD, Carney JM, Tatsumo T, Stadtman ER, Floyd RA, Markesbery WR 1992. Protein oxidation in aging brain. Ann N Y Acad Sci. 663:110-119.

Tan DX, Zanghi BM, Manchester LC, Reiter RJ 2014. Melatonin identified in meats and other food stuffs: potentially nutritional impact. J Pineal Res. 57:213-218.

Tang G, Yang GY 2016. Aquaporin-4: a potential therapeutic target for cerebral edema. Int J Mol Sci. 17.

Tarasoff-Conway JM, Carare RO, Osorio RS, Glodzik L, Butler T, Fieremans E, Axel L, Rusinek H, Nicholson C, Zlokovic BV, Frangione B, Blennow K, Menard J, Zetterberg H, Wisniewski T, de Leon MJ 2015. Clearance systems in the brain-implications for Alzheimer disease. Nat Rev Neurol. 11:457-470.

Vacas MI, Cardinali DP 1979. Diurnal changes in melatonin binding sites of hamster and rat brains. Correlations with neuroendocrine responsiveness to melatonin. Neurosci Lett. 15:259-263. 
Waldhauser F, Saletu B, Trinchard-Lugan I 1990. Sleep laboratory investigations on hypnotic properties of melatonin. Psychopharmacology (Berl). 100:222-226.

Weishaupt JH, Bartels C, Polking E, Dietrich J, Rohde G, Poeggeler B, Mertens N, Sperling S, Bohn M, Huther G, Schneider A, Bach A, Siren AL, Hardeland R, Bahr M, Nave KA, Ehrenreich $\mathrm{H}$ 2006. Reduced oxidative damage in ALS by high-dose enteral melatonin treatment. J Pineal Res. 41:313-323.

Winkler A, Auer C, Doering BK, Rief W 2014. Drug treatment of primary insomnia: a meta-analysis of polysomnographic randomized controlled trials. CNS Drugs. 28:799816.

Wu YH, Zhou JN, van HJ, Jockers R, Swaab DF 2007. Decreased MT1 melatonin receptor expression in the suprachiasmatic nucleus in aging and Alzheimer's disease. Neurobiol Aging. 28:1239-1247.

Xu J, Wang LL, Dammer EB, Li CB, Xu G, Chen SD, Wang G 2015. Melatonin for sleep disorders and cognition in dementia: a meta-analysis of randomized controlled trials. Am J Alzheimers Dis Other Demen. 30:439-447.

Yulug B, Hanoglu L, Kilic E 2017. Does sleep disturbance affect the amyloid clearance mechanisms in Alzheimer's disease? Psychiatry Clin Neurosci. 71:673-677.

Zdanys KF, Steffens DC 2015. Sleep disturbances in the elderly. Psychiatr Clin North Am. 38:723-741.

Zeppenfeld DM, Simon M, Haswell JD, D'Abreo D, Murchison C, Quinn JF, Grafe MR, Woltjer RL, Kaye J, Iliff JJ 2017. Association of perivascular localization of aquaporin-4 with cognition and Alzheimer disease in aging brains. JAMA Neurol. 74:91-99.

Zhang W, Chen XY, Su SW, Jia QZ, Ding T, Zhu ZN, Zhang T 2016. Exogenous melatonin for sleep disorders in neurodegenerative diseases: a meta-analysis of randomized clinical trials. Neurol Sci. 37:57-65 
Figure Legends.

Figure 1. The three different "bodies," wakefulness, slow-wave sleep (NREM sleep) and REM sleep, must necessarily follow each another harmoniously to ensure health. Upper panel: a 76-year old man sleeping $8 \mathrm{~h}$ daily will live 50 years in the physiological state of wakefulness, 20 years in slow-wave sleep and 6 years in REM sleep. Lower panel: reduction of $25 \%$ of sleep over the last 40 years leads to predominance of the wakefulness state and reduction of the slow-wave sleep, associated with cardiovascular disease, metabolic syndrome, obesity, and type II and type III diabetes. The age-related reduction in slow wave sleep further adds to the unbalanced of physiological states with obvious consequences for health, such as obesity, high blood pressure and diabetes, and neurodegenerative diseases.

Figure 2. Upper panel. Aging, sleep disruption, and glymphatic pathway impairment interact to promote $A \beta$ plaque deposition in the aging brain. (a) Loss of slow wave sleep and astrogliosis are frequent features in the aging brain. (b) Reduced slow wave activity impairs glymphatic $A \beta$ clearance, which is maximal in the sleeping brain. (c) Loss of slow wave sleep also increases $A \beta$ formation. (d) Astrogliosis associated with aging, small vessel disease, traumatic brain injury, or amyloid plaques is associated with impaired glymphatic pathway function. (d) The presence of $A \beta$ aggregates specifically inhibits slow wave activity (modified from Boespflug and lliff, 2018). Lower panel. Melatonin counteracts most of the dysfunctions observed (blue arrows). 
Figure 1
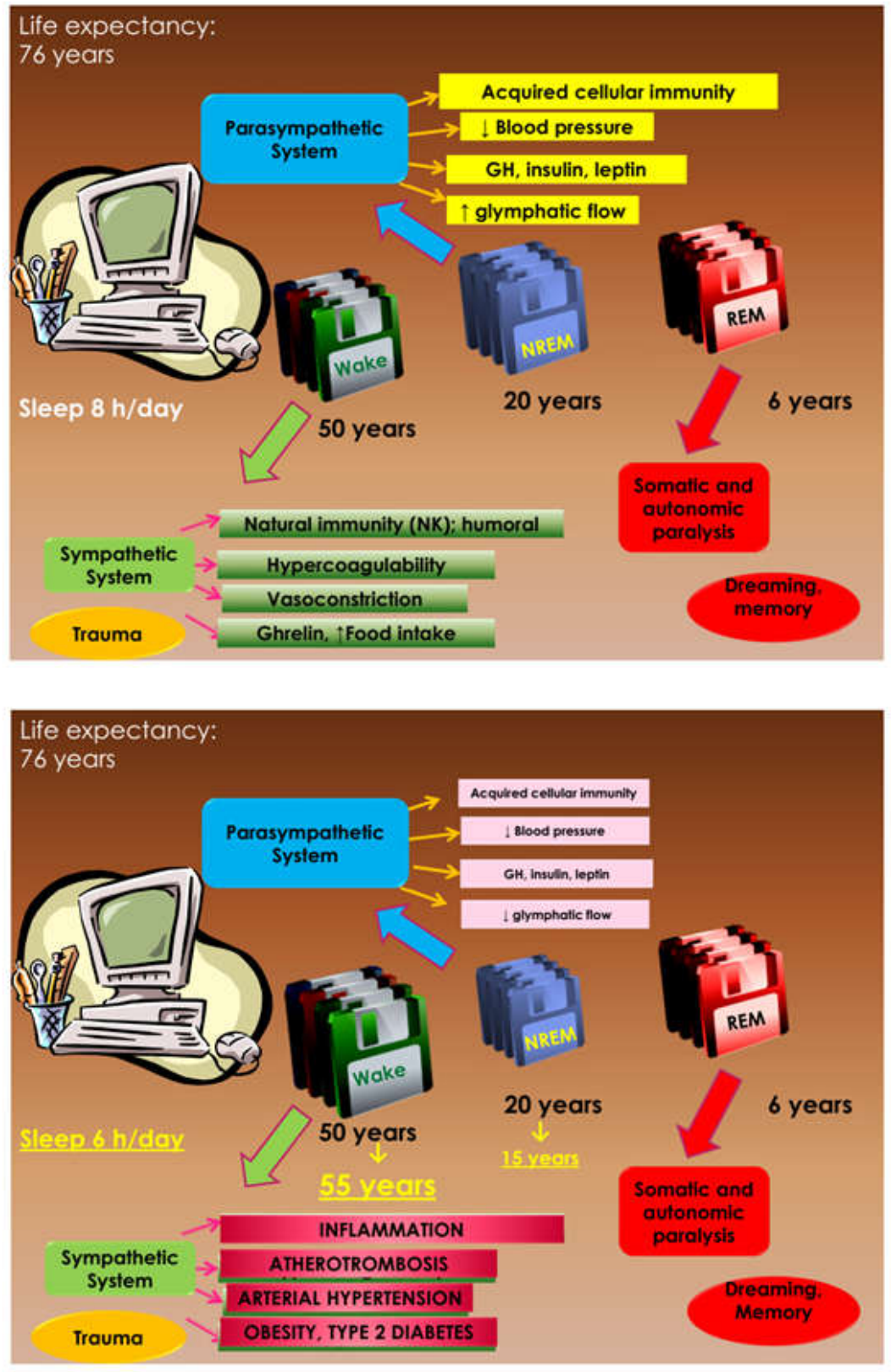
Figure 2
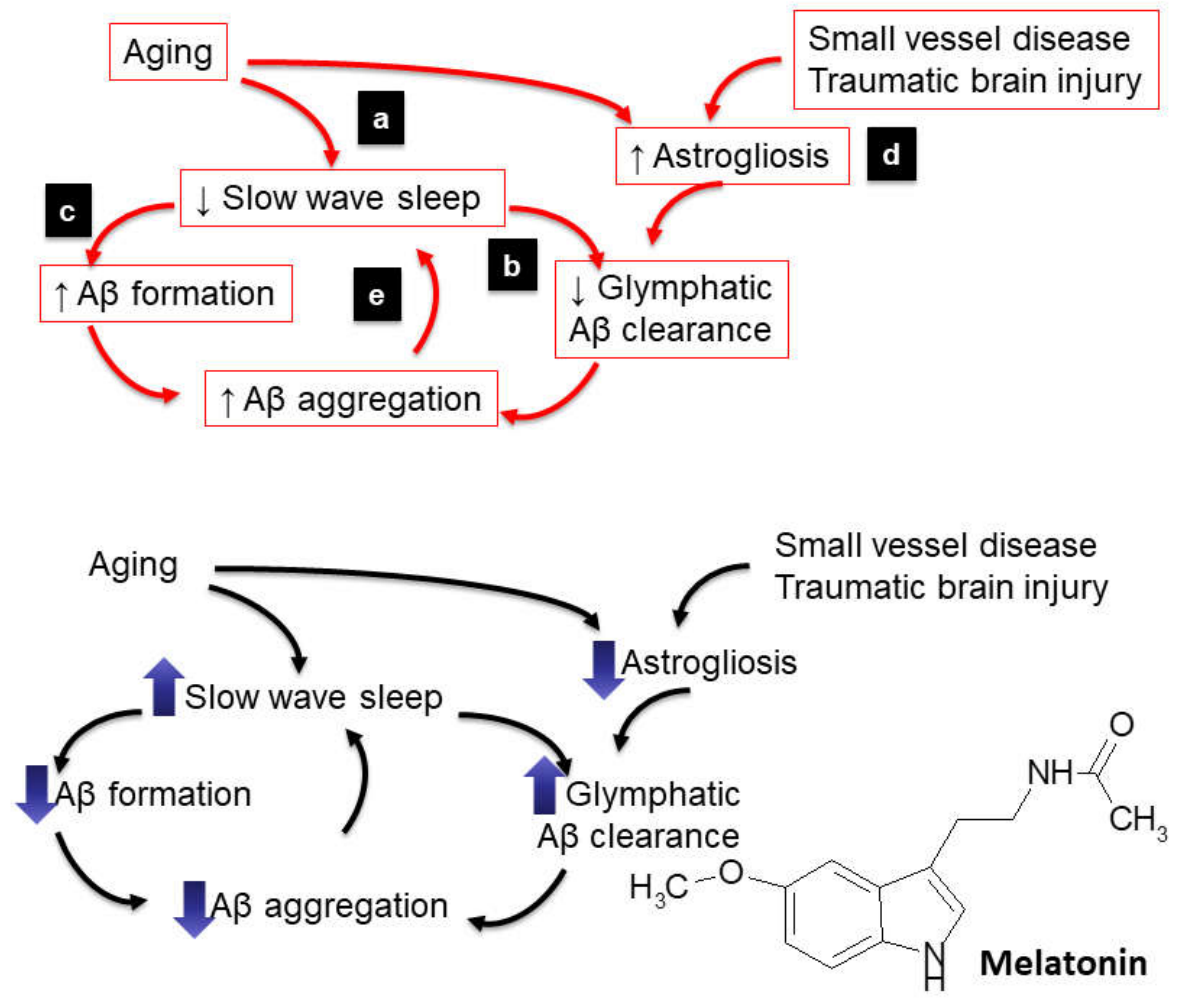